\title{
Perception of Final Year Dental Students on Pattern of Medication for Pulpitis
}

\author{
Ashfaq Akram ${ }^{1,2 *}$, Nabishah Mohamad ${ }^{1}$, Abdus Salam $^{1}$, Dalia Abdullah ${ }^{3}$ and Ruzana zamzam ${ }^{4}$ \\ ${ }^{1}$ Department of Medical Education, Universiti Kebangsaan Malaysia (UKM), Malaysia \\ ${ }^{2}$ Faculty of Medicine, Allianze University College of Medical Sciences (AUCMS), Malaysia \\ ${ }^{3}$ Department of Operative Dentistry, Universiti Kebangsaan Malaysia (UKM), Malaysia \\ ${ }^{4}$ Department of Psychiatric, Universiti Kebangsaan Malaysia (UKM), Malaysia
}

\begin{abstract}
Background: Numerous studies have examined the pattern of various analgesics and antibiotics prescribed by primary dental health care practitioners to manage irreversible pulpitis.
\end{abstract}

Aim: To determine the pattern of medicines for irreversible pulpitis in undergraduate dental students.

Methodology: A cross sectional survey of open ended questionnaire based on dental scenarios of irreversible pulpitis for child, pregnant woman and apical periodontitis for man was carried out at department of operative dentistry. The questionnaire sought mock medications by the 5 th year undergraduate dental students. Responses $(n=111)$ were collected and analysed by frequency for drug prescribed. Data included the name of medicines, dose and presentation of the drugs.

Results: Of the 57 distributed questionnaires, $37(63 \%)$ respondents returned completed forms. A total of 24 $(64.8 \%)$ of the respondents were female. Majority of mock prescriptions $(97.4 \%)$ had a combination of antibiotics and analgesics to male patients having apical periodontitis. Almost $25 \%$ suggested antibiotics to the pregnant women of $1^{\text {st }}$ trimester, while $81.9 \%$ suggested antibiotic and analgesic in tablet form to a child patient. In analgesic and antibiotics groups, acetaminophen $(75.5 \%)$ and amoxicillin $(56.7 \%)$ were highest respectively. Abbreviated drug name $(11.7 \%$ analgesic and $0.9 \%$ antibiotic), and incorrect strengths (7.3\% antibiotics and $14 \%$ analgesics) were found.

Conclusion: Amoxicillin and acetaminophen were primary medication for irreversible pulpitis. More clinical training on medication is suggested.

Keywords: Analgesics; Antibiotics; Dental students; Irreversible pulpitis; Medication

\section{Introduction}

Dental medications, as complementary component of treatment of various dental procedures to get relief of dental pain, comprise of analgesics and antibiotics [1,2]. Prescribing medication varies from 74 - $97 \%$ in dental practice during a week [3]. In the UK, 40\% dentists prescribe antibiotics in a week [4]. More than $50 \%$ dental prescriptions have antibiotic, analgesic and mouthwash [5]. In Brazil, the most commonly prescribed medications by dental practitioners were amoxicillin (26\%) and diclofenac (35\%) [6]. Dar-Odeh et al. [7] found amoxilcillin $(60 \%)$ and metronidazole $(39.4 \%)$ as higher prescribed antibiotics by dentists in Jorden. Chate et al. [8] observed the pattern of prescribing antibiotics and found $21.4 \%$ prescriptions with error associated with abbreviation of drug name, dose and strength.

Most studies on medication pattern involve the qualified dental graduates. Limited data is available on undergraduate dental students in this aspect. Dental training aims to acquire prescribing skill by dental students. Thus clinical instructors of dental schools take technical skills as the primary component of a 'good' dentist [9]. Undergraduate dental students, though, are not allowed to prescribe medicines; they are trained to prescribe medicines under supervision of clinical teachers.

This study aimed to find the pattern of medicines suggested by final year undergraduate students for irreversible pulpitis and apical periodontitis. An ethical approval was obtained from the Research Committee of Faculty of Medicine, Universiti Kebangsaan Malaysia.

\section{Methodology}

A cross sectional survey having open ended questionnaires was used. The questionnaire comprised of three scenarios based on dental problems of a child, pregnant woman and man. The provided mock scenarios had diagnosis such as irreversible pulpitis for child and pregnant woman and apical periodontitis for man. Thus each surveyor prescribed mock medications for three multiple patients. Thirty seven out of 57 students completed the survey of mock prescriptions. Responses $(n=111)$ were analysed by frequency and percentage. Data included the name and type of medicines, dose and presentation of the drugs.

\section{Results}

Of the distributed 57 questionnaires, 37 (63\%) students returned completed mock prescriptions. A total of $24(64.8 \%)$ of the respondents were female. The acetaminophen (75.5\%) and amoxicillin (56.7\%) were the primary medications (Table 1 ).

Majority of students (97.4\%) prescribed a combination of antibiotics and analgesics to a man with apical periodontitis. Almost $25 \%$ students suggested antibiotics and analgesic to the pregnant woman of $1^{\text {st }}$ trimester with irreversible pulpitis. A large number

*Corresponding author: Ashfaq Akram, Department of Medical Education Faculty of Medicine, Universiti Kebangsaan Malaysia (UKM), Jalan Yaqaab HUKM, Cheras, Kuala Lumpur 56000, Malaysia, Tel: 06-03 91457973; Fax: 06-03 91738790; E-mail: ashfaqakram@hotmail.com

Received February 23, 2012; Accepted April 18, 2012; Published April 20, 2012

Citation: Akram A, Mohamad N, Salam A, Abdullah D, Zamzam R (2012) Perception of Final Year Dental Students on Pattern of Medication for Pulpitis. Dentistry 3: 159. doi:10.4172/2161-1122.1000159

Copyright: @ 2012 Akram A, et al. This is an open-access article distributed under the terms of the Creative Commons Attribution License, which permits unrestricted use, distribution, and reproduction in any medium, provided the original author and source are credited. 
Citation: Akram A, Mohamad N, Salam A, Abdullah D, Zamzam R (2012) Perception of Final Year Dental Students on Pattern of Medication for Pulpitis. Dentistry 3: 159. doi:10.4172/2161-1122.1000159

Page 2 of 3

\begin{tabular}{|c|c|c|c|c|c|c|c|}
\hline \multicolumn{4}{|c|}{ Analgesic $(n=111)$} & \multicolumn{4}{|c|}{ Antibiotic $(n=52)$} \\
\hline Medicine & No. students & Frequency & Percentage & Medicine & No. Students & Frequency & Percentage \\
\hline Acetaminophen & 28 & 84 & 75.7 & Amoxicillin & 21 & 30 & 56.7 \\
\hline Mefnemic acid & 08 & 24 & 21.6 & Metronidazole & 15 & 21 & 40.4 \\
\hline Others & 01 & 3 & 2.7 & Others & 01 & 1 & 2.7 \\
\hline Total & 37 & 111 & 100 & Total & 37 & 52 & 100 \\
\hline
\end{tabular}

Table 1: Mock Medicines by Dental Students for Irreversible Pulpitis.

\begin{tabular}{|c|c|c|c|}
\hline \multirow[t]{2}{*}{ Type of patient } & \multirow[t]{2}{*}{ Medicine group } & \multicolumn{2}{|c|}{$\begin{array}{l}\text { Students } \\
\mathrm{N}=37\end{array}$} \\
\hline & & Frequency & $\%$ \\
\hline \multirow{2}{*}{ Child } & Analgesic & 30 & 81.1 \\
\hline & Antibiotic \& Analgesic & 7 & 18.9 \\
\hline \multirow{3}{*}{ Pregnant women } & Analgesic & 28 & 75.7 \\
\hline & Antibiotic & 1 & 2.7 \\
\hline & Antibiotic \& Analgesic & 8 & 21.6 \\
\hline \multirow{3}{*}{ Adult men } & Analgesic & - & - \\
\hline & Antibiotic & 1 & 2.7 \\
\hline & Antibiotic \& Analgesic & 36 & 97.3 \\
\hline
\end{tabular}

Table 2: Pattern of mock medicines by dental students for irreversible pulpitis.

(75.5\%) of mock medications had analgesic primarily acetaminophen while one had sole antibiotic (2.7\%) for the $1^{\text {st }}$ trimester pregnant woman. To an eight year child with irreversible pulpitis, more than two third (81.9\%) suggested antibiotic and analgesic in tablet form (Table 2). Abbreviated drug name ( $11.7 \%$ analgesic and $0.9 \%$ antibiotic), the incorrect strengths (7.3\% antibiotics and $14 \%$ analgesics) and incorrect dose upto 20 percent were found (Table 3).

In summary, acetamionphen (75.7\%), amoxicillin (56.7 \%) and metronidazole (40.4\%) were the common suggested medicines for irreversible and apical periodontitis. However some prescribing errors were found in mock prescriptions of dental students.

\section{Discussion}

In dental practice, along procedures, antibiotics and analgesics are prescribed. The most used antibiotics like amoxicillin, penicillin, metronidazole and amoxicillin and clavunate are prescribed by dentists [10-16]. Though performing pelpectomy is the best management of irreversible pulpitis but prescribing medication is still part of practical dental practice. In US, more than $60 \%$ endodontists prescribe penicillin VK as the first choice of antibiotic followed by $57 \%$ clindamycin and erythromycin (26.65\%) [17]. This study primarily focused on the pattern

\begin{tabular}{|l|c|c|c|c|}
\hline $\begin{array}{l}\text { Drug related } \\
\text { Errors }\end{array}$ & $\begin{array}{l}\text { Analgesic } \\
(\mathrm{n}=111)\end{array}$ & Percent & $\begin{array}{l}\text { Antibiotic } \\
(\mathrm{n}=52)\end{array}$ & Percent \\
\hline Incorrect dose & 7 & 6.3 & 8 & 15.3 \\
\hline Incorrect strength & 15 & 13.5 & 4 & 7.6 \\
\hline Abbreviated name & 13 & 11.7 & 1 & 1.9 \\
\hline Drug form (syrup) child* & 7 & 18.9 & - & - \\
\hline Drug form (tablet )child* & 30 & 81.9 & - & - \\
\hline Child* $(\mathrm{n})=37$ & & & & \\
\hline
\end{tabular}

Child* $^{*}(n)=37$

Table 3: Commission Errors of Mock Prescription of Dental Students. of medicines, suggested by undergraduate dental students for pulpitis either irreversible or periapical. Acetaminophen was the most highly (76.7\%) prescribed medicines for irreversible and periapical pulpitis (Table 1). Donaldson \& Goodchild [18] found that acetaminophen and NSAIDs were the most appropriate choices for the treatment of acute dental pain such as Pulpitis.

Many studies have shown that amoxicillin is the first choice of antibiotic and commonly prescribed (40- 60 percents) for irreversible pulpitis [19-22]. From Table 1, it is evident that the most commonly prescribed antibiotic was amoxicillin (57.7\%) for irreversible pulpitis as well as apical periodontitis. The pattern of suggesting medicines by undergraduate dental students was similar to graduate dentists. In this study, students suggested, though limited, antibiotics, amoxicillin 57.7 percent and metronidazole 40.4 percent. All other antibiotics were 1.9 percent. The reason could be the less clinical experience.

The administration of penicillin requires analgesics to be added in the regime to reduce dental pain significantly [23]. Majority of dental students suggested amoxicillin in combination of acetaminophen (Table 2). This shows a similar pattern of dental medication of students and it is hoped that dental students would follow the same pattern in their real practice upon graduation.

Many studies indicate acetaphinomen and ibuprofen are effective therapy for dental pain taken after dental procedure especially extraction or even before procedure [24,25]. In this study, students suggested almost three quarters (75-80 percent) analgesic mainly acetaphinomen especially for child and pregnant woman. This shows a similar pattern on analgesics; however, students prescribed a limited analgesics and antibiotics variety. It could be due to less ward training and less interaction with patients.

Children's dosage is based on a single dose of $10 \mathrm{mg}$ acetaminophen per kilogram bodyweight which can be repeated 4-6 hourly per 24 hours. Acetaminophen in syrup form or oral suspension is recommended for a child up to 12 year of age [25]. The results show 
almost $81.9 \%$ mentioned tablet form medicine for 8 year child (Table 2). From guideline of pharmacology, a child of eight year old should be given medicine in syrup form [26]. Syrup (liquid) form is easy to take as compared to tablet form. However, in clinical practice, patient (child)' consent is taken before prescribing any form of medicine. Due to absence of real child patient, students might not have taken this aspect. They concentrated on choice of drug rather than form of drug.

Table 2 illustrates the drug description for pregnant woman of $1^{\text {st }}$ trimester. Almost one fifth students (21.6 percent) suggested antibiotic and analgesics. Medication of amoxicillin is in safe zone while metronidazole is contraindicated in $1^{\text {st }}$ trimester [27]. Almost 40 percent responses contained antibiotics for pregnant woman. In practice, doctors prefer to avoid prescribing antibiotics in $1^{\text {st }}$ trimester of pregnancy. The students were under clinical training and they followed the guidelines of books. This could be the reason of suggesting antibiotics in $1^{\text {st }}$ trimester of pregnancy. The facts indicated of more clinical training on medication process of patient management. Bottom of Form

\section{Conclusion}

Dental students in mock prescriptions prescribed acetaminophen and amoxicillin as the analgesic and antibiotic agents for irreversible pulpitis. However, for multiple choices and selection of drugs, less variety of multiple medications was found which suggested more clinical training of dental students.

\section{References}

1. Doyle G, Javawardena S, Ashraf E, Cooper SA (2002) Efficacy and tolerability of non prescription ibuprofen versus celecoxib for dental pain. J Clin Pharmacol 42: $912-919$

2. Morse Z, Tump A, Kevelham E (2006) Ibuprofen as a pre-emptive analgesic is as effective as rofecoxib for mandibular third molar surgery. Odontology 94 : 59-63.

3. Hind V, Waterhouse PJ, Maguire A, Tabari D, Lloyd J (2009) Developing a primary dental care outreach (PDCO) course-part-1: practical issues and evaluation of clinical activity. Euro J Dent Educ 13: 203-209.

4. Lewis MA, (2008) Why we must reduce dental prescription of antibiotics: European Union antibiotic awareness day. Br Dent J 205: 537-538.

5. Dar-Odeh N, Ryalat S, Shayyab M, Abu-Hammad O (2008) Analysis of clinical records of dental patients attending Jordan University Hospital:Documentation of drug prescription and local anaesthetic injections. Ther Clin Risk Manag 4: 1111-1117.

6. Mendonca JM, Lyra DP Jr, Rabelo JS, Siqueira JS, Balisa-Rocha BJ, et al. (2010) Analysis and detection of dental prescribing errors at primary health care units in Brazil. Pharm World Sci 32: 30-35.

7. Dar-Odeh, NS, Abu-Hammad OA, Khraisat AS, El Maaytah MA, Shehabi A (2008) An analysis of therapeutic, adul antibiotic prescriptions issued by dental practitioners in Jordan. Chemotherapy 54: 17-22.

8. Chate RA, White S, Hale LR, Howat AP, Bottomley J, et al. (2006) The impact of clinical audit on antibiotic prescribing in general dental practice. Br Dent $\mathrm{J}$ 201: 635-641.

9. Buck D, Malik S, Murphy N, Patel V, Singh S, et al. (2000) What makes a good dentist and do recent trainees make the grade? The views of vocational trainers. Br Dent J 189: 563-566.

10. Palmer NO, Martin MV, Pealing R, Ireland RS (2000) An analysis of antibiotic prescriptions from general dental practitioners in England. J Antimicrob Chemother 46: 1033-1035.

This article was originally published in a special issue, Biomechanics and Clinical Dentistry handled by Editor(s). Dr. Kenko Jian-hong Yu, China Medical University, China
11. Demirbas F, Gjermo PE, Preus HR (2006) Antibiotic prescribing practices among Norwegian dentists. Acta Odontol Scand 64: 355-359.

12. Al-Haroni M, Skaug N (2007) Incidence of antibiotic prescribing in dental practice in Norway and its contribution to national consumption. J Antimicrob Chemother 59: 1161-1166.

13. Al-Mubarak S, Al-Nowaiser A, Rass MA, Alsuwyed A, Alghofili A, et al. (2004) Antibiotic prescription and dental practice within Saudi Arabia; the need to reinforce guidelines and implement speciality needs. J Int Acad Periodontol 6: 47-55.

14. Al-Haroni M, Skaug N (2006) Knowledge of prescribing antimicrobials among Yemeni general dentists. Acta Odontol Scand 64: 274-280.

15. Sarkar C, Das B, Baral P (2004) An audit of drug prescribing practices of dentists. Indian J Dent Res 15: 58-61.

16. Murti A, Morse Z (2007) Dental antibiotic prescription in Fijian adults. Int Dent J 57: 65-70.

17. Yingling NM, Byrne BE, Hartwell GR (2002) Antibiotic Use by Members of the American Association of Endodontists in the year 2000: Report of a National Survey. J Endod 28: 396-404.

18. Donaldson M, Goodchild JH (2010) Appropriate analgesic prescribing for the general dentist. Gen Dent 58: 291-297.

19. Rodriquez-Nunez A, Cisneros-Cabello R, Velasco- Ortega E, Llamas-Carreras JM, Tórres-Lagares D, et al. (2009) Antibiotic use by members of the Spanish Endodontic Society. J Endod 35: 1198-1203.

20. Segura-Egea JJ, Velasco-Ortega E, Torres-Lagares D, Velasco-Ponferrada MC, Monsalve-Guil L, et al. (2010) Pattern of antibiotic prescription in the management of endodontic infections amongst Spanish oral surgeons. Int Endod J 43: 342-350.

21. Salako NO, Rotimi VO, Adib SM, Al-Mutawa S (2004) Pattern of antibiotic prescription in the management of oral diseases among dentists in Kuwait. J Dent 32: 503-509.

22. Mainjot A, D'Hoore W, Vanheusden A, Van Nieuwenhuysen JP (2009) Antibiotic prescribing in dental practice in Belgium. Int Endod J 42: 1112-1117.

23. Nagle D, Reader A, Beck M, Weaver J (2000) Effect of systemic penicillin on pain in untreated irreversible pulpitis. Oral Surg Oral Med Oral Pathol Oral Radiol Endod 90: 636-640.

24. Møller PL, Nørholt SE, Ganry HE, Insuasty JH, Vincent FG, et al. (2000) Time to onset of analgesia and analgesic efficacy of effective acetaminophen 1000 $\mathrm{mg}$ compared to tablet acetaminophen $1000 \mathrm{mg}$ in postoperative dental pain a single -dose, double -blind randomized, placebo-controlled study. J Clin Pharmacol 40: 370-378.

25. Olson NZ, Otero AM, Marrero I, Tirado S, Cooper S, et al. (2001) Onset of analgesia for liquigel ibuprofen $400 \mathrm{mg}$, acetaminophen $1000 \mathrm{mg}$, ketoprofen $25 \mathrm{mg}$ and placebo in the treatment of postoperative dental pain. $\mathrm{J}$ Clin Pharmacol 41: 1238-1247.

26. Dinesh Mehta (2000) British National Formulary. Pharmaceutical Press 40.

27. George R Sratto, Adrienne L Woods (2008) Nurse's drug handbook. The information standard for prescription drugs and nursing considerations. Thomson learning Inc. 